\title{
Food related antibodies in headache patients
}

\author{
J MERRETT, RC PEATFIELD, ${ }^{*}$ F CLIFFORD ROSE, $†$ TG MERRETT \\ From the RAST Allergy Unit, Benenden Chest Hospital, Cranbrook, Kent, Leeds General Infirmary, ${ }^{*}$ \\ Princess Margaret Migraine Clinic, Charing Cross Hospital, London, $\dagger U K$
}

SUMmaRY Highly sensitive and specific methods for assaying IgE and IgG4 for antibodies in serum have been developed in order to test a recent suggestion that food allergy is a major cause of migraine. Sera were collected from 208 adults -74 with dietary migraine, 45 with non-dietary migraine, 29 with cluster headache and 60 controls. No significant differences were identified between any of the groups with the one exception that cluster headache patients had significantly raised levels of total serum IgE: this difference may be explained by the high proportion of smokers. Mean IgG4 titres to cheese, milk and chocolate were very similar in the dietary and non-dietary migraine patients and the control subjects, though lower in the cluster headache patients. There was, therefore, no evidence that the food intolerance often associated with migraine headaches is associated with a conventional allergic mechanism.

A minority of migraine patients report that headaches can be precipitated by specific foods; the commonest of these among 494 migraine patients attending the Princess Margaret Migraine Clinic, Charing Cross Hospital, London, were cheese (19\% sensitive), chocolate (18\% sensitive) and citrus fruit (11\% sensitive). ${ }^{1}$ These particular foods are all believed to have a high content of amines such as tyramine, but evidence that headaches can be reliably reproduced by the administration of pure tyramine remains conflicting. ${ }^{12}$

Immunologically mediated skin and gastrointestinal responses to foods are now well established ${ }^{3}$ and there is evidence of circulating immune complexes and complement activation before attacks of common migraine, though not in classical migraine. ${ }^{4}$ Although elevated total serum IgE levels were no commoner in migraine or tension headache patients, ${ }^{5}$ evidence was recently presented that two thirds of severely affected migraine patients were allergic to some foods. ${ }^{6}$ Although these authors confirmed the clinical observation by the use of the Radioallergosorbent test (RAST), the reported IgE levels seemed rather low; perhaps partly due to non-specific binding in the in-vitro test.

This paper re-investigates the role of IgE-mediated food allergy in migraine by using a highly sensitive IgE RAST technique to determine circulating levels

Address for reprint requests: Dr TG Merrett, RAST Allergy Unit, Benenden Chest Hospital, Cranbrook, Kent TN17 4AX, UK

Received 12 February 1983. Accepted 14 April 1983 of specific IgE to four foods commonly supposed to "trigger" migraine. Specific IgG4 levels to the same foods were also quantified because it has been suggested $^{8}$ that IgG4 is the short-term sensitising IgG described by Parish ${ }^{9}$ and that it is responsible for the late response seen in some cases of asthma. ${ }^{10}$

\section{Patients and methods}

Serum samples were taken from a total of 148 headache patients attending the Princess Margaret Migraine Clinic at Charing Cross Hospital. Of these 119 had migraine fulfilling Vahlquist's criteria," 60 with classical and 59 with common migraine. Seventy-four patients (14 men and 60 women) reported that headaches were definitely precipitated by cheese, chocolate or citrus fruit, and 45 (14 men and 31 women) that headaches could not be precipitated by such foods. A disproportionate number of the "dietary" patients were selected for inclusion in this survey. 29 patients (24 men and 5 women) with cluster headache were included as a control group. In a second series of experiments 60 normal subjects ( 30 men and 30 women) drawn at random from a population survey, were compared with a random selection of patients from the dietary and non-dietary migraine groups and with all the subjects in the cluster headache group.

\section{IgE measurements}

Total serum IgE was determined by conventional radioimmunoassay (RIA) using the fast double-antibody separation technique ${ }^{12}$ and results expressed in international units per ml. Phadebas RAST (Pharmacia GB Ltd, Hounslow, England) was used to quantify circulating IgE antibodies against three common UK inhalant allergens and four foods-Timothy grass pollen (Phleum pratense), house- 
dust mite (Dermatophagoides pteronyssinus), cat epithelium, cow's milk, cheese, cocoa-bean and orange. The manufacturer's assay procedure was modified by increasing the first incubation from three hours to overnight and the patients' serum volume from $50 \mu$ lo $100 \mu$ l: this resulted in a two-fold increase in assay sensitivity and a relative decrease in non-specific binding to allergen-discs. Nonspecific binding varied from $0.6 \%$ to $1.3 \%$ according to allergen and was allowed for in the calculations. Results were expressed as the percentage of a weakly-positive serum (Phadebas RAST "D" reference serum); 50-199\% being interpreted as "weakly-positive" and over $200 \%$ as strongly positive.

\section{IgG4 measurements}

Immunosorbent-purified anti-IgG4 (Dutch Red Cross, Amsterdam), labelled with iodine- 125 by the chloramine $T$ method $^{13}$ to a specific radioactivity of approximately $15 \mu$ $\mathrm{Ci} / \mu \mathrm{g}$, was used to quantify both total and specific IgG4 antibody. ${ }^{14}$ Briefly, total and serum IgG4 was determined by a one-hour RIA in which a $50 \mu \mathrm{IgG} 4$ sample competed with $100 \mu \mathrm{l}$ radio-labelled anti-IgG4 for binding to $100 \mu \mathrm{l}$ of CNBr-activated microcrystalline cellulose-IgG4 particles. $^{15}$

The assay was controlled with milk-positive reference serum which bound $15 \%$ of ${ }^{125} \mathrm{I}$-anti IgG4 in the assay, and hypogammaglobulinaemic serum which bound $0 \cdot 8-1 \cdot 2 \%$ of the tracer, depending on the allergen tested. Results were expressed in arbitrary units $\mathrm{IgG} 4 / \mathrm{ml}$ : for example, 100 units $\mathrm{IgG} 4 / \mathrm{ml}$ refers to a test sample which bound as much tracer as the reference serum. A figure of 15 units $\mathrm{IgG} 4 / \mathrm{ml}$ was associated with a count rate approximately three times that associated with hypogammaglobulinaemic serum, and this was taken to be a positive result. Statistical analyses were carried out using Student's $t$ test on log-transformed data and the null hypothesis rejected when $\mathrm{p}<0.05$.

\section{Results}

Total IgE-Geometric mean values and $95 \%$ confidence intervals for the dietary and non-dietary migraine patients and those with cluster headache are shown in fig 1: there was no significant difference between the two groups of migraine patients, but those with cluster headache were significantly higher $(p<0.01)$ than those of all the migraine patients taken together. There were no significant differences between 23 patients whose cluster headache was active and the remaining six whose headaches were quiescent at the time of sampling. Smoking data was available in 19 male cluster headache subjects - 16 subjects smoked more than five cigarettes daily with a geometrical mean IgE titre of 65.9 units; only three subjects smoked less than five cigarettes daily, their mean IgE level was $16 \cdot 8$ units.

\section{IgE to specific allergens (fig 2)}

Responses to grass, mite and cat antigens were normal (averaging $20 \%$ of the subjects positive) and there were no differences between the three patient

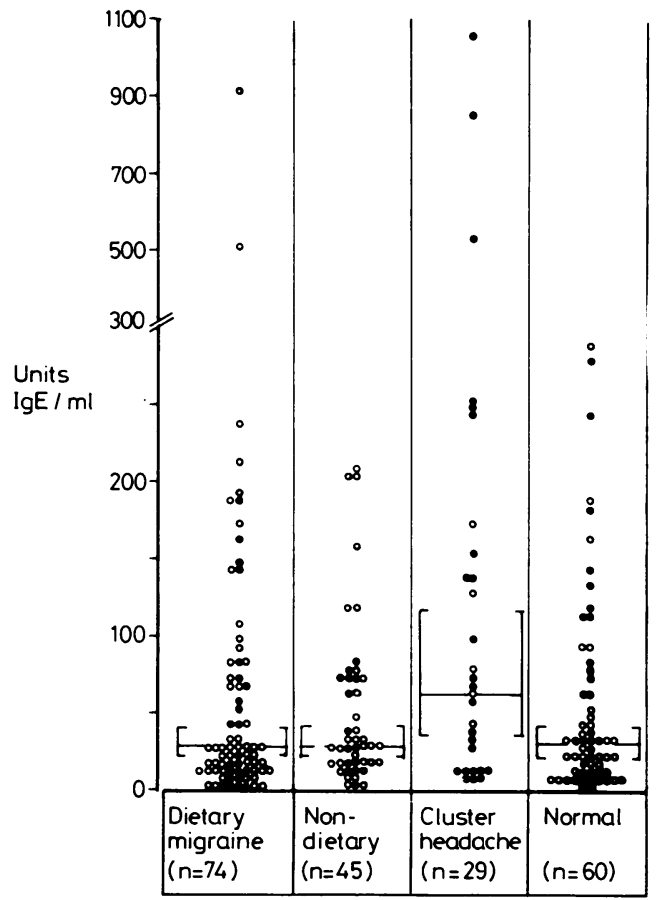

Fig 1 Geometric mean total serum IgE levels, (and $95 \%$ confidence intervals for each mean ([ ]) are shown for the patient groups. It will be noted that the majority of migraine cases are female $(\mathrm{O})$, but that cluster headache is more common among males (O).
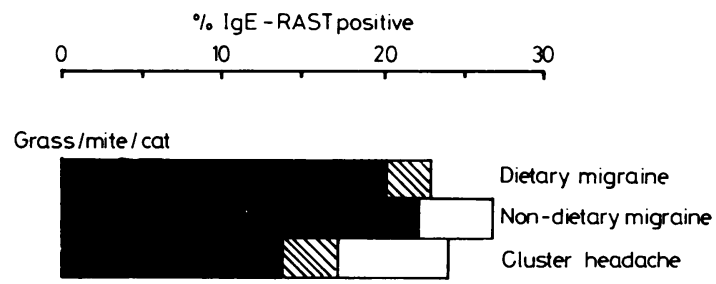

Milk / cheese/chocolate / orange

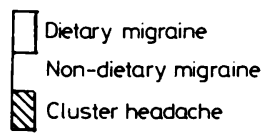

Fig 2 Results of IgE-RAST expressed as RAST classes $1 / 2(\square), 1$ or higher ( show that IgE antibodies to the three most common UK inhalant allergens (grass pollen, house dust mite and cat epithelium) were found with normal frequency (about 20\%) in each patient group, but IgE antibodies to foods were rarely identified. 


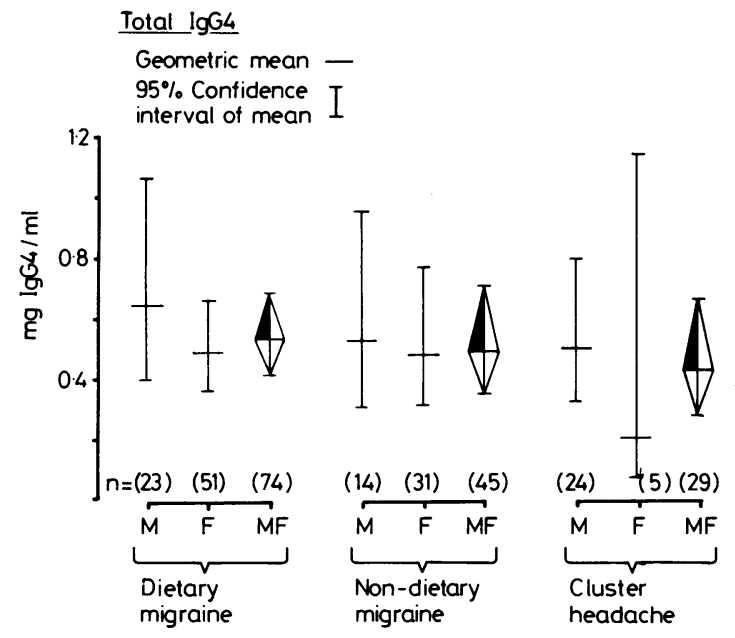

Fig 3 Geometric mean total serum IgG4 levels, and $95 \%$ confidence intervals for each mean, are shown for the patient groups. Each group is also analysed according to gender.

groups. Only one dietary migraine patient out of 74 had a weakly positive response to cheese and one of the 29 cluster headache patients was also positive, also to cheese.

\section{Total IgG4}

Geometric mean levels in the dietary and non-dietary migraine patients and for cluster headache patients were very similar. (fig 3 ).

\section{Specific IgG4}

These were rarely even weakly positive to inhaled antigens, but were more frequently strongly positive to the foods tested, but this was to an equal extent in the dietary and non-dietary migraine patients (fig 4). The cluster headache group, in contrast, had lower titres $(\mathrm{p}<0.05)$ to dietary antigens and $D$ pteronyssinus than the migraine groups. The significance of this finding was explored by repeating the assay for cheese-related IgG4 in all the cluster headache patients, a random selection of those with migraine and a group of control subjects (fig 5). Detectable antibody was found in a minority of all the patient groups except those with cluster headache, which appear to have a very narrow distribution of antibody titres.

\section{Discussion}

Our finding that there are no differences in total or food-specific IgE levels between our dietary and nondietary subjects makes us unable to confirm the suggestion of Monro et al $^{6}$ that $75 \%$ of severe migraine patients have raised levels of food-specific IgE antibodies. Our modification of the manufacturers' IgE-RAST procedure increased the percentage binding to the reference serum two-fold, thus lowering the limit for reliable detection of specific IgE. The variability of non-specific binding we allowed for $(1.3 \%$ for cocoa bean) was of the same order of magnitude as the results Monro et al interpreted as positive-it is likely that we would have interpreted at least some of them as negative. We found no differences in total IgG4 in any of our subject groups. Although occasional high titres to food related IgG4 antibodies were encountered in migraine patients, they were not
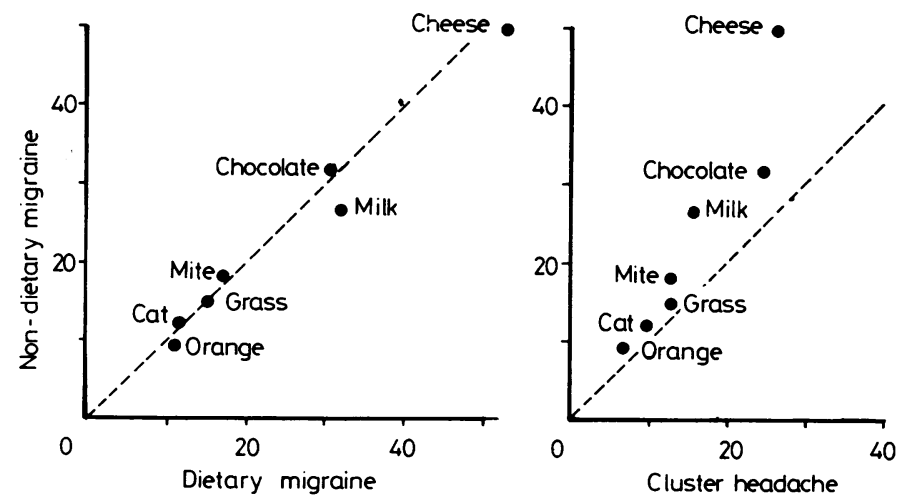

Fig 4 Geometric means of specific IgG4-RAST results were calculated for each patient group. Dietary and nondietary migraine patient means were similar but cluster headache patients tended to have lower mean values, especially for cheese. 


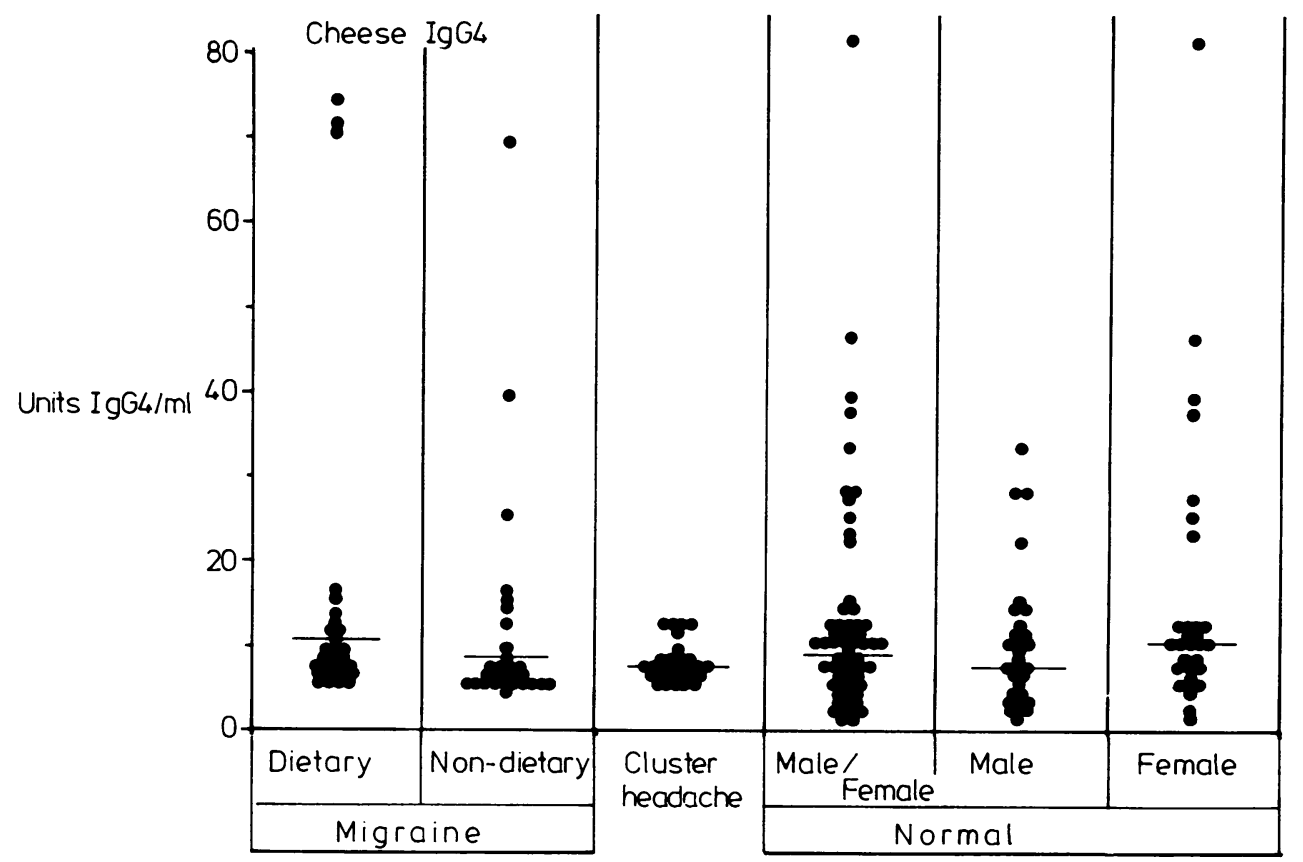

Fig 5 Scattergram for cheese-specific IgG4-RAST results in which each patient group is compared to the normal group which is divided according to gender.

differently distributed than the dietary and nondietary patients and we found no evidence to suggest they are relevant to the pathogenesis of headache. In a recent community survey ${ }^{14}$ we found that $63 \%$ of women had raised IgG4 levels to egg and $40 \%$ to milk, with less than $3 \%$ having raised levels to grass, mite or cat allergens.

Our findings in the cluster headache patients were unexpected. There is no clinical or epidemiological evidence of food-precipitated headache in this disease, though most patients can precipitate headaches by alcohol. Total IgE levels were significantly higher than those of either the migraine patients or controls, even when the study is confined to male subjects, but specific inhalant or food related antibody titres were not elevated. The geometric mean $\mathrm{IgE}$ levels in the cluster headache group $(62.4 \mathrm{u} / \mathrm{ml})$ was similar to that reached in non-atopic patients with respiratory disease ${ }^{16}$ where it was speculated that this may, at least part, be due to smoking habits, because men tend to have higher total IgE levels than women and usually are the heavier smokers. ${ }^{17}$ The explanation for the high IgE levels in our cluster headache patients may indeed lie in the disproportionate number of smokers; whether the headache is a cause or a consequence of the excessive smoking remains uncertain.

In contrast total IgG4 levels were within normal limits, but occasional patients with elevated titres to these foods, common in all other populations studied, were found.

The clinical significance of these immunological disturbances is uncertain but may be related to the excess of mast cells found in the skin in the area of the $\mathrm{e}^{1819}$ headache with degranulation during the active phase and also the favourable response often seen to corticosteroids. ${ }^{21}$

We thank the Post Office and Civil Service Sanatorium Society for supporting this study and Pharmacia Diagnostics AB for a generous supply of food allergen discs.

\section{References}

' Glover V, Littlewood J, Sandler M, Peatfield R, Petty R, Clifford Rose F. Biochemical predisposition to dietary 
migraine - the role of phenolsulphotransferase. Headache 1983;23:53-8.

${ }^{2}$ Kohlenberg RJ. Tyramine sensitivity in Dietary Migraine: A critical review. Headache 1982;22:30-4.

${ }^{3}$ Lessof MH, Wraith DG, Merrett TG, Merrett J, Buisseret PD. Food allergy and intolerance in 100 patients-local and systemic effects. $Q J$ Med 1980; 49:259-71.

4 Lord GDA, Duckworth JW. Complement and immune complex studies in migraine. Headache 1978;18: 225-60.

5 Medina JL, Diamond S. Migraine and Atopy. Headache 1976;16:271-4.

- Monro J, Brostoff J, Carini C, Zilkha K. Food allergy in migraine. Lancet 1980;ii:1-4.

7 Merrett TG, Gawel MJ, Peatfield RC. Food allergy in migraine. Lancet 1980; ii:532.

* Stanworth DR, Smith AK. Inhibition of reaginmediated PCA reactions in baboons by the human IgG4 subclass. Clin Allergy 1973;3:37-41.

${ }^{9}$ Parish WE. Short-term anaphylactic IgG antibodies in human sera. Lancet 1970;ii:591-2.

${ }^{10}$ Gwynn CM, Ingram J, Almousawi T, Stanworth DR. Bronchial provocation tests in atopic patients with allergen-specific IgG4 antibodies. Lancet 1982;ii: 254-6.

"Vahlquist B. Migraine in children. Int Arch Allergy Appl immunol 1955;7:348-55.

12 Merrett TG, Merrett J. Methods of quantifying circulating IgE. Clin Allergy 1978;8:543-57.

${ }^{13}$ Greenwood FC, Hunter WM, Glover JS. The preparation of 131 I-labelled human growth hormone of high specific radioactivity. Biochem J 1963;89:114-23.

14 Merrett J, Burr ML, Merrett TG. A community survey of IgG4 antibody levels. Clin Allergy. In press.

is Wide L. Radioimmunoassays employing immunosorbents. Acta Endocrinologica 1969;63:Suppl.142, 207-21.

16 Pantin CFA, Merrett TG. Smoking and IgE levels. $\mathrm{Br}$ Med J 1982;284:744.

17 Lee PN ed. Statistics of Smoking in the UK 7th ed. London: Tobacco Research Council 1976;66-7.

18 Liberski PP, Pruzinski A. Further observations on the mast cells over the painful region in cluster headache patients. Headache 1982;22:115-7.

19 Appenzeller O, Becker WJ, Ragaz A. Cluster headache-ultra structural aspects and pathogenetic mechanisms. Arch Neurol 1981;38:302-6.

${ }^{20}$ Sjaastad O, Sjaastad OV. Urinary histamine excretion in migraine and cluster headache. J Neurol 1977;216: 91-104.

21 Jammes JL. The Treatment of Cluster Headaches with prednisone. Diseases of the Nervous System 1975;36: 375-6. 